NASA Technical Memorandum 100932 AIAA-88-3403

NASA-TM-100932

19880015302

\title{
Thermodynamic Modeling of the No-Vent Fill Methodology for Transferring Cryogens in Low Gravity
}

David J. Chato

Lewis Research Center

Cleveland, Ohio

Prepared for the

24th Joint Propulsion Conference cosponsored by the AIAA, ASME, SAE, and ASEE Boston, Massachusetts, July 11-13, 1988 


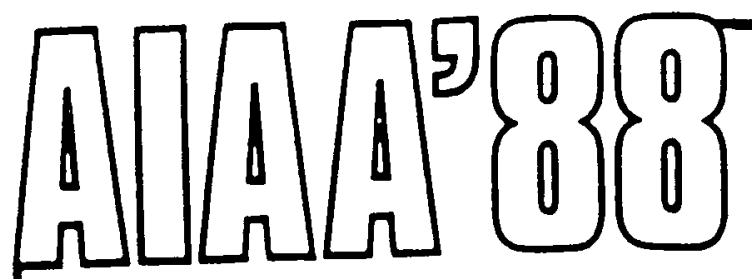

AIAA-88-3403

Thermodynamic Modeling of the No-Vent

Fill Methodology for Transferring

Cryogens in Low Gravity

David J. Chato, Lewis Research Center,

Cleveland, $\mathrm{OH}$

\section{AIAA/ASME/SAE/ASEE 24th JOINT PROPULSION CONFERENCE JULY 11-13, 1988/Boston, Massachusetts}


THERMODYNAMIC MODELING OF THE NO-VENT FILL METHODOLOGY FOR TRANSFERRING CRYOGENS IN LOW GRAVITY

David J. Chato*

National Aeronautics and Space Administration

Lewls Research Center

Cleveland, Ohio 44135

\section{Abstract}

The filling of tanks with cryogens in the lowgravity environment of space poses many technical challenges. Chief among these is the inability to vent only vapor from the tank as the fllling proceeds. As a potential solution to this problem. the NASA Lewis Research Center (NASA Lewis) is researching a technique known as No-Vent Fill. This technology potentially has broad application. The focus of this paper is the fueling of space based Orbital Transfer Vehicles.

This paper describes the fundamental thermodynamics of the No-Vent Fill process to develop an analytical model of No-Vent Fill. The model is then used to conduct a parametric investigation of the key parameters: initial tank wall temperature, liquid-vapor interface heat transfer rate, liquid inflow rate and inflowing liquid temperatures. Liquid inflowing temperature and the liquid-vapor interface heat transfer rate seem to be the most significant since they influence the entire fill process. The initial tank wall temperature must be sufficlently low to prevent a rapid pressure rise during the initial liquid flashing stage, but then becomes less significant.

\section{Nomenclature}

$\begin{array}{ll}\text { A } & \text { area } \\ \text { Cv } & \text { speciflc heat at constant volume } \\ \bar{h} & \text { enthalpy } \\ k & \text { thermal Conductivity } \\ \text { L } & \text { characteristic length } \\ M & \text { mass } \\ \dot{m} & \text { mass flow rate } \\ q & \text { heat flux } \\ Q & \text { heat Input } \\ T & \text { temperature } \\ t & \text { time } \\ U & \text { total internal energy } \\ u & \text { internal energy per unit mass } \\ V & \text { volume } \\ W & \text { work } \\ \dot{W} & \text { rate of work }\end{array}$

\section{* Member AIAA}

This paper is declared a work of the U.S. Government and is nol subject in copyright protection in the Uniled States.

\author{
$\alpha \quad$ thermal diffusivity \\ $p$ density \\ Subscripts: \\ cond condensate \\ fgas flashing gas \\ fliq flashing liquid \\ gas ullage gas \\ in inlet \\ inf interface \\ ig between liquid and gas \\ liq bulk liquid \\ sat saturation \\ sgas saturated gas \\ sliq saturated liquid \\ tank tank \\ wall tank wall
}

\section{Introduction}

Many fluid management issues face the designer of systems for filling tanks with cryogens on-orbit. The most important of these are the large rate of generation of vapor from the residual energy stored in cryogenic tank walls, the uncertainty of liquid and vapor distributions in a tank in low gravity, and the need to keep maximum tank pressure low to reduce tank mass. During a normal gravity fill a top vent is kept open to vent the vapor generated during the fill process thereby maintaining a low tank pressure. If the same approach is used in low gravity the ullage gas may never vent. Instead of venting vapor, large amounts of liquid may be dumped overboard. If liquid is vented from one side of a nonpropulsive vent and vapor from the other side, the spacecraft may tumble out of control. To prevent the loss of liquid, the spacecraft may be placed in an artificial gravity field by continuous thruster firing to position the ullage at a vent opening, but this may require dedicated thrusters and additional propellent. The problems of low-g fluid management and the thruster technique for liquid positioning have been described previousiy by Lacovic.l For the fill operation, maintaining control between the tanker spacecraft and the spacecraft being refueled while thrusting may be difficult due to potentialiy large shifts in the center of gravity. In some instances, such as a depot based at a space station, thrusting may be impractical due to large system size. The No-Vent Fill technique, first analyzed in detail by Merino, is a methodology whereby these problems are eliminated. 2 
The No-Vent Fill methodology is as follows: The tank wall is prechilled to a temperature sufficient to remove most of the thermal energy from it. The tank is evacuated by venting to space, and liquid is then injected through spray nozzles and/or mixing jets to promote liquid-vapor heat exchange. The tank can be filled without venting as long as the prechill is sufficient and the liquid-vapor heat exchange keeps the liquid and vapor close to thermodynamic equilibrium.

In the main body of this paper, a model for the initial flashing stage (when tank pressure is less than the liquid saturation pressure) is formulated. A model for the later stages, which preserves the temperature difference between the bulk liquid and the vapor, is also formulated. These two models are combined to provide a transient model of the No-Vent Fill process. A computer program was developed to solve the model equations, and then used to conduct a parametric study of the No-Vent Fill process. Parameters investigated include: initial tank wall temperature, interface heat transfer, liquid inflow rate, and inflowing liquid temperature.

\section{No-Vent Fill Theory}

General

Following the tank chilldown and evacuation, liquid inflow is started. Liquid is injected through spray nozzles and/or mixing jets to promote liquid-vapor heat exchange. The initial inflow partially flashes while entering, and vaporizes on striking the tank wall. This removes the remaining residual energy from the tank walls and raises the tank pressure to near saturation conditions. The continuing inflow of liquid elther condenses or compresses the vapor allowing more liquid to enter. For a period of time condensation dominates and tank pressure remains fairly constant. Eventually vapor compression takes over. The tank pressure rises rapidly to the limit pressure, and the fill process must be stopped. It is the objective of No-Vent Fill technique to postpone the compression phase as long as possible.

To understand the No-Vent Fill concept it is helpful to examine the thermodynamics of the Fill process. It can be shown by an equilibrium analysis of the thermodynamics that, with a sufficiently low temperature of the entering liquid, the end state of a full tank should be at an acceptably low pressure. Unfortunately like all real processes. the fill process does not proceed at thermodynamic equilibrium. Major sources of nonequilibrium behavior are as follows: (1) energy transfer from the initlally warm tank to the entering fluid, (2) heat flux into the tank during the fill process, (3) flashing of the liquid during the initial low pressure stages of the fill, and (4) temperature gradients within and between the tank, the vapor, and the liquid.

A model which separates the vapor and liquid phases is needed to determine the effect of temperature differences and the rate of heat transfer between the two phases. Since the initial flashing stage of the flow is controlled by different phenomena than the condensation and compression stages, the model will be divided into two parts. For simplicity, heat flux into the tank during the fill process will be assumed to be negligible.

\section{Liquid Flashing Stage}

The initial flashing stage is modeled as follows. The high heat transfer rates found in bolling make it unlikely that much liquid will remain in the tank until the wall is chilled to near the incoming liquid temperature. When the tank pressure is less than the saturation pressure of the incoming liquid, the liquid inflow will flash resulting in a gaseous inflow which enters the ullage vapor directly and a liquid stream which is cooled to the saturated state corresponding to the current tank pressure. This liquid stream then strikes the tank wall and is assumed to be quickly vaporized to a saturated vapor. A comparison between the heat transfer rates of $f i l m$ bolling of the liquid stream and gaseous conduction into the ullage gas (the comparison is included in an appendix to this report) indicates that the effects of wall-gas heat transfer are secondary as long as conduction is the predominate heat transfer mechanism. For simplicity the effects of wall-gas heat transfer will be assumed negligible. The formulation presented here only accounts for the tank wall energy removed by the vaporizing liquid stream.

The equations for this stage are:

Inflow energy balance at the liquid inlet

$$
\dot{m}_{i n} h_{i n}=\dot{m}_{f g a s} h_{\text {sgas }}+\dot{m}_{f l i q}{ }^{h} s l i q
$$

Initial flashing mass balance

$$
\dot{\mathrm{m}}_{\mathrm{in}}=\dot{\mathrm{m}}_{\mathrm{fgas}}+\dot{\mathrm{m}}_{\mathrm{fliq}}
$$

Wall energy balance

$$
-M_{w a l 1} \frac{d\left(C_{v} T\right)}{d t}=\dot{m}_{f l i q}\left(h_{\text {sgas }}-h_{s l i q}\right)
$$

Gas mass balance

$$
\frac{d M_{g a s}}{d t}=\dot{m}_{f g a s}+\dot{m}_{f l i q}
$$

Gas energy balance

$$
\frac{d\left(M_{g a s} U_{g a s}\right)}{d t}=\left(\dot{m}_{f g a s}+\dot{m}_{f l i q}\right) h_{s g a s}
$$

Rearranging Eq. (1) and substituting Eq. (2) into Eq. (1)

$$
\dot{m}_{i n} h_{i n}=\left(\dot{m}_{i n}-\dot{m}_{f l i q}\right)_{s g a s}=\dot{m}_{s l i q} h_{f l i q}
$$

or

$$
\dot{m}_{i n}\left(h_{i n}-h_{g a s}\right)=\dot{m}_{f 11 q}\left(h_{s 11 q}-h_{s g a s}\right)
$$

Substituting Eq. (7) into (3)

$$
-M_{\text {wall }} \frac{d\left(C_{v} T\right)}{d t}=\dot{m}_{\text {in }}\left(h_{\text {sgas }}-h_{\text {in }}\right)
$$

Substituting Eq. (2) into (4)

$$
\frac{d M_{\text {gas }}}{d t}=\dot{m}_{\text {in }}
$$

and into $\mathrm{Eq}$. (5) 


$$
\frac{d\left(M_{\text {gas }} u_{g a s}\right)}{d t}=\dot{m}_{i n} h_{\text {sgas }}
$$

Expanding Eq. (5) and using the results of (9) and (10):

$$
M_{\text {gas }} \frac{d u_{g a s}}{d t}=\dot{m}_{i n}\left(h_{s g a s}-u_{g a s}\right)
$$

For the times when the tank pressure is above the inflowing liquid saturation pressure, Eqs. ( 8 ), (9), and (11) can be written directly as the mass and energy equations for the Fill process. Once the liquid and wall temperatures are equal the residual wall energy is negligible and the model can be switched to the condensation and compression stage equations.

\section{Vapor Condensation and Compression Stage}

To study the relation between gas and liquid the fluid is broken into three nodes: gas, liquid and interface. A mass and energy balance can be written for each node.

Gas mass balance:

$$
\frac{d M_{\text {gas }}}{d t}=-\dot{m}_{\text {cond }}
$$

Gas energy balance:

$$
\begin{aligned}
\frac{d\left(M_{g a s} u_{g a s}\right)}{d t}=M_{g a s} \frac{d u_{g a s}}{d t} & +\dot{m}_{\text {cond }} u_{g a s} \\
& =\dot{m}_{\text {cond }} h_{g a s}+\dot{W}_{1 g}
\end{aligned}
$$

Liquid mass balance:

$$
\frac{d M_{11 q}}{d t}=\dot{m}_{i n}+\dot{m}_{c o n d}
$$

Liquid energy balance:

$$
\begin{array}{r}
M_{1 i q} \frac{d u_{1 i q}}{d t}+u_{1 i q} \frac{d M_{1 i q}}{d t}+a_{i n f}+\dot{m}_{i n} h_{i n}+\dot{m}_{c o n d} h_{i q} \\
=\dot{w}_{1 g}
\end{array}
$$

The interface node has some unique features. It is assumed to be a infinitesimally thin layer between the liquid and gas. Since it is infinitesimally thin, it can store neither mass nor energy. This makes the equations for the interface as follows:

Interface mass balance:

$$
\frac{d M_{i n f}}{d t}=0
$$

Interface energy balance:

$$
q_{1 n f}+\dot{m}_{\text {cond }} h_{1 q q}=\dot{m}_{\text {cond }} h_{\text {gas }}
$$

Some additional equations are needed to solve this set of equations. qinf is determined by a convective heat transfer equation. Heat transfer from the gas side can be neglected because gas thermal conductivity is much smaller than liquid thermal conductivity for the fluids of interest in this document. The main effects of the gas is the mass transport of energy already accounted for in Eq. (17). ainf is then a function of liquid side heat transfer. Writing this as a convective equation:

$$
q_{\text {inf }}=\bar{h} A_{\text {inf }}\left(T_{\text {inf }}-T_{1 i q}\right)
$$

It can be shown by kinetic theory that:

$$
T_{\text {inf }}=T_{\text {sat }} \text {. }
$$

Combining Eqs. (17) to (19).

$$
\dot{m}_{\text {cond }}=\frac{\vec{h}_{A_{\text {inf }}\left(T_{\text {sat }}-T_{1 i q}\right)}}{\left(h_{g a s}-h_{1 i q}\right)}
$$

The work on the gas can be calculated from basic thermodynamics for a control volume:

$$
W=P d V
$$

If the pressure rise is not too great:

$$
\dot{W}_{1 g}=P_{g a s} \frac{d V_{g a s}}{d t}
$$

In a tank of constant volume:

$$
V_{\text {gas }}=V_{1 i q}=\text { constant }
$$

From Eq. (23):

$$
-\frac{d V_{g a s}}{d t}=\frac{d V_{11 q}}{d t}
$$

From Eq. (24)

$$
\frac{d V_{1 i q}}{d t}=-\frac{1}{\rho_{1 i q}}\left(\dot{m}_{i n}+\dot{m}_{c o n d}\right)
$$

So:

$$
\dot{W}_{1 g}=\frac{\rho_{\text {gas }}}{\rho_{11 q}}\left(\dot{m}_{1 \mathrm{n}}+\dot{m}_{\text {cond }}\right)
$$

Equations (12) to (17), (20), and (26) along with the thermodynamic equations of state form a fairly complete model of the No-Vent Flll process. The chief source of thermodynamic inefficiency is the work term $\dot{W}_{1 g}$. The major independent variables in this analysis are $\dot{m}_{i n}, h_{i n}, T_{w a l l}$, and $v_{\text {tank }}$.

\section{Analysis}

The equations for the two stage model are sufficiently complex that a closed form solution is not possible. A computer algorithm called NVFILL has been written to solve the equations using a finite difference approximation. The variables $\dot{m}_{i n}, h_{i n}, \bar{h}$, and $v_{\text {tank }}$ are inputs to the code and held constant throughout a run. $T_{\text {wall }}$ is set at the start. Ainf is defined as the surface area of a sphere whose volume is that of $V_{\text {gas }}$. the gas volume which changes with time.

During the initial flashing stage, the computational algorithm adds the mass added to the 
ullage during the timestep, calculates a new ullage density internal energy and enthalpy, and then uses the density and enthalpy to determine a new ullage pressure. In the condensationcompression stage the problem is solved by a twostep calculation procedure. For the first step, the ullage is held at constant pressure while a interfacial mass transfer rate is calculated. For the second step, a new liquid volume is calculated from the liquid inflow, interfacial mass transfer and current bulk liquid conditions. The ullage vapor is then compressed adiabatically to fill the remaining tank volume. The time step for both these processes combined is set to $10^{-3} \mathrm{hr}$ which is sufficiently small compared to the process rates for most cases of interest to insure a good approximation of the continuous liquid inflow, interfacial mass transfer and vapor compression processes. The computational algorithm terminates when the tank is 95 percent full with liquid or the tank pressure exceeds 60 psia.

\section{Results and Discussion}

Many differing tank sizes and geometries exist in the 1 terature for Orbit Transfer Vehicle (OTV) designs. To provide a comparison with previous work, the OTV tank parameters employed by DeFelice and Aydelott are used. 3 These OTV parameters are summarized in Table 1. The baseline OTV parameters in Table 1 are representative of an unmanned space based OTV and are expected to be the sizes used in an initial operational space based OTV. Only the hydrogen tankage is examined since previous work indicates that the fill transients in the hydrogen tankage are the most severe.?

The effect of initial tank temperature on the tank pressure, as filling proceeds, is shown in Fig. 1. The $218.3 \mathrm{~K}\left(393^{\circ} \mathrm{R}\right)$ temperature was the suggested initial tank temperature from Ref. 3 . It produces a large initial pressure transient and causes the tank to fill at a much higher pressure than the other initial tank temperatures investigated. The $152.8 \mathrm{~K}\left(275^{\circ} \mathrm{R}\right)$ initial condition was selected as a wall temperature which will ralse the pressure in the tank just above the stagnation pressure of the incoming liquid at the end of the vapor flashing stage. A temperature of $55.6 \mathrm{~K}$ $\left(100^{\circ} \mathrm{R}\right)$ was selected as a likely minimum temperature, below which little effect on tank pressure results because all the tank energy has been essentially removed. It can be seen from $F i g$. I that even though the $55.6 \mathrm{~K}\left(100^{\circ} \mathrm{R}\right)$ initial tank temperature transitions from the wall chilldown to the compression/condensation stage at about $130 \mathrm{kPa}$ ( 15 psia) bulk bolling in the liquid raises the tank fill pressure characteristics to near the $152.8 \mathrm{~K}\left(275^{\circ} \mathrm{R}\right)$ line for the majority of the fill process.

Reference 3 selected the initial tank temperature based on a criterla which yielded the desired fill level at the end of the fill using a thermodynamic equilibrium analysis to predict the end state. The initial pressure transient it produces was not accounted for in the Ref. 3 analysis and may be undesirable because of the control problems it poses for tanks with strict maximum pressure requirements. The stagnation pressure requirement used to select the intermediate initial wall temperature is probably a better criteria for initial wall temperature since it minimizes the initial pressure transient. Consequently, the $152.8 \mathrm{~K}$
(275 ${ }^{\circ} R$ ) wall temperature was used for the rest of the No-Vent Fill studies.

Previous work on fluid mixing give wide ranges of surface heat transfer coefficients. 4-6 To cover the range of expected values, heat transfer coefficients spanning the range of two decades from 5.68 to $568 \mathrm{~W} / \mathrm{m}^{2} \mathrm{~K}$ (1 to $\left.100 \mathrm{Btu} / \mathrm{ft}^{2} \mathrm{hr}{ }^{\circ} \mathrm{R}\right)$ were parametrically evaluated. As can be seen in Fig. 2 (data from $\mathrm{Fig} .1$ assumed $56.8 \mathrm{~W} / \mathrm{m}^{2} \mathrm{~K}$ [10 Btu/ft $\left.{ }^{2} \mathrm{hr}{ }^{\circ} \mathrm{R}\right]$ ), heat transfer coeffictent has a significant effect on the tank pressure response during the No-Vent Fill process. For the smallest heat transfer coefficient, tank pressure exceeds $414 \mathrm{kPa}$ ( $60 \mathrm{psia}$ ) prior to completion of the fill process. This is the only analysis run which did not terminate at 95 percent full. The highest heat transfer coefficient produces hardly any pressure rise beyond the initial flashing stage.

The $56.8 \mathrm{~W} / \mathrm{m}^{2} \times\left(10 \mathrm{Btu} / \mathrm{ft}^{2} \mathrm{hr}{ }^{\circ} \mathrm{R}\right)$ heat transfer coefficient was selected as a estimate for NoVent Fill calculations for the rest of the study. Heat Transfer rates above this are likely to be achieved only by using forced convection to promote liquid-vapor heat transfer.

Figure 3 shows the tank pressure response for No-Vent Fills at liquid inflow rates at $453.5 \mathrm{~kg} / \mathrm{hr}$ $(10001 \mathrm{bm} / \mathrm{hr}), 907 \mathrm{~kg} / \mathrm{hr}(2000 \mathrm{lbm} / \mathrm{hr}$, Table 1 rate) and $1814 \mathrm{~kg} / \mathrm{hr}(4000 \mathrm{Tbm} / \mathrm{hr})$. Although the curves are fairly close for most of the fill process there is a significant difference in the final pressure with the highest pressure corresponding to the highest flow rate.

Figure 4 shows fills at various inflowing 1/quid temperatures corresponding to saturation pressures of $34.5 \mathrm{kPa}(5 \mathrm{ps} 1 \mathrm{a}), 103 \mathrm{kPa}(15 \mathrm{psia})$ and $172 \mathrm{kPa}$ (25 psia). Inflowing liquid temperature shows a very strong effect on the No-Vent Fill process. This is to be expected given the dependence of the condensation rate on temperature difference. For real spacecraft. subatmospheric subcooling (lowering the liquid temperature below the saturation temperature at atmospheric pressure) may be difficult to achieve so $103 \mathrm{kPa}$ ( $15 \mathrm{psia}$ ) was used as the baseline for the other parametric runs. The pronounced effect of subcooling ind cates that further investigation of heat exchangers to cool the liquid inflow is probably worthwhile.

\section{Concluding Remarks}

Several areas for model improvement can be suggested as a result of this study. Most evident is the need for a more accurate correlation relating the interfacial heat transfer rate to the independent parameters of No-Vent Fill. Two different correlations are under investigation currently but are dependent on liquid injection technique; one for droplet sprays through the ullage, and a second for turbulent jet mixing of the bulk liquid. In most real transfer systems the inflow rate will not be constant but will be controlled by the pressure difference between the liquid supply and the tank being filled. A model which links the flow rate to the tank pressure variation is being developed. The effects of wall-vapor and vapor-liquid heat transfer on the initial vapor flashing stage which were neglected in the analysis of this paper are under continued investigation. Several proposed injection techniques for No-Vent Fill show the potential for promoting forced convection in 
the vapor thus raising the wall vapor heat transfer rate much closer to the liquid bolling heat transfer rate. The exact heat transfer correlations for these conditions are still being determined.

The results of these parametric investigations help define areas of research where the No-Vent Fill process should be studied. Several ground test experiments are being prepared at NASA Lewis to study the controlling phenomena. One experimental apparatus will employ 1 iquid Nitrogen as the test fluid and provide controlled flows of liquid and gas which can be used to study heat transfer and condensation on the liquid interface. A small portable experimental test rig capable of being operated in a remote area with $\mathrm{LH}_{2}$ is also being fabricated. This test rig will be used to study the effect of thermal subcooling and injection technique on the No-Vent Fill process. In addition. NASA Lewis is reactivating a large cryogenic vacuum chamber to allow No-Vent fill testing with $\mathrm{LH}_{2}$ on large scale tankage. Initial testing for this facility will investigate the effects of initial tank temperatures and in flow rate, as well as provide proof of concept testing for the No-Vent Fill technique. It is hoped that the combined results from the portable and large scale tests will provide the data necessary to determine interfacial heat and mass transfer rates and verify the No-Vent Fill analytical models.

Although ground testing can be used to investigate key phenomena, it is only in the lowgravity environment where the fluid dynamics and heat transfer mechanisms combine to give a true simulation of the Low-Gravity No-Vent Fill process. To investigate the effect of a Low-Gravity environments, several approaches are either under development or being planned. NASA Lewis has had good success with Computational Fluid Dynamic codes to model low-gravity flows. An effort is underway to adapt these codes to the No-Vent Fill problems. NASA Lewis is undertaking studies for the design of a free flying spacecraft called the Cryogenic Orbiting Liquid Depot Satellite (COLD-SAT) to study fluid management issues with liquid hydrogen in space. The study of No-Vent Fill is one of the primary experiments to be conducted on the COLD-SAT. Although a $\mathrm{LH}_{2}$ experiment such as COLD-SAT is required to understand the technology completely, NASA Lewis is also exploring small scale low-gravity experiments which can provide precursory data for COLD-SAT and allow for a more focused COLD-SAT design.

\section{Appendix}

To estimate the heat transferred from the tank wall to the ullage vapor by means of solid conduction, the vapor is approximated as a semi-infinite slab of gaseous hydrogen. Schneider gives as the solution for the total heat input for a semiinfinite slab. 7

$$
\frac{Q}{A}=2 k \sqrt{\frac{t}{\pi \alpha}}\left(T_{w a l l}-T_{g a s}\right)
$$

Gaseous Hydrogen at $101.3 \mathrm{kPa}(15 \mathrm{ps}$ ia) has the following property values: 8

$$
T_{\text {gas }}=20.268 \mathrm{~K} \quad\left(36.6^{\circ} \mathrm{R}\right)
$$

$k=0.01694 \mathrm{~W} / \mathrm{K} \mathrm{m}\left(0.00979 \mathrm{Btu} / \mathrm{ft}^{2} \mathrm{hr}{ }^{\circ} \mathrm{R}\right)$

$$
\alpha=0.00375 \mathrm{~m}^{2} / \mathrm{hr}\left(0.04037 \mathrm{ft}^{2} / \mathrm{hr}\right)
$$

For a typical fill

$$
\begin{gathered}
T_{\text {wall }}=152.8 \mathrm{~K}\left(275^{\circ} \mathrm{R}\right) \\
t=0.055 \mathrm{hr}
\end{gathered}
$$

(for the duration of the flashing stage.)

Substituting these values into Eq. (Al)

$$
\frac{Q}{A}=9.69 \mathrm{Whr} / \mathrm{m}^{2}\left(3.07 \mathrm{Btu} / \mathrm{ft}^{2}\right)
$$

Dividing by the time of the flashing stage to obtain an average heat flux

$$
\frac{\mathrm{q}}{\mathrm{A}}=176 \mathrm{~W} / \mathrm{m}^{2}\left(55.8 \mathrm{Btu} / \mathrm{ft}^{2} \mathrm{hr}\right)
$$

Brentari and Smith give as the minimum film boiling heat flux for liquid hydrogen a value of approximate ly: ${ }^{9}$

$$
\frac{\mathrm{q}}{\mathrm{A}}=8.5 \times 10^{3} \mathrm{~W} / \mathrm{m}^{2}\left(2.69 \times 10^{3} \mathrm{Btu} / \mathrm{ft} \mathrm{t}^{2} \mathrm{hr}\right)
$$

The gaseous conduction heat flux is therefore only 2.1 percent of the minimum heat flux to be found in the film boiling process.

\section{References}

1. Lacovic, R.F., et. al, "Management of Cryogenic Propellants in a Full-Scale Orbiting Space Vehicle," NASA TN D-4571, 1968.

2. Merino, F., Blatt, M.H., and Thies, N.C., "Fllling of Orbital Fluid Management Systems," (CASD-NAS-78-010, General Dynamics Convair Division, San Diego, CA, July 1978), NASA CR-159404.

3. Defelice, D.M., and Aydelott, J.C., "Thermodynamic Analysis and Subscale Modeling of Space-Based Orbit Transfer Vehicle Cryogenic Propellant Resupply," AIAA Paper 87-1764. June 1986. (NASA TM 89921.)

4. Aydelott, J.C., "Modeling of Space Vehicle Propellant Mixing," NASA TP-2107, 1983.

5. Dominick, S.M., "Mixing Induced Condensation Inside Propellant Tanks," AIAA Paper 84-0514, Jan. 1984.

6. Meserole, J.S., Jones, O.S., Brennan, S.M., and Fortini, A., "Mixing-Induced Ullage Condensation and Fluid Destratification," AIAA Paper 87-2018, June 1987.

7. Schneider, P.J., Conduction Heat Transfer, Addison-Wesley, Cambridge, MA, 1955.

8. McCarty, R.D., "Hydrogen Technological Survey - Thermophysical Properties," NASA SP-3089, 1975.

9. Brentari, E.G., and Smith, R.V.M "Nucleate and Film Pooling Design Correlations for $\mathrm{O}_{2}, \mathrm{~N}_{2}$, $\mathrm{H}_{2}$ and $\mathrm{H}_{e}$," Advances in Cryogenic Engineering, Vol. 10, Sect. 2, K.D. Timmerhaus, ed., Plenum Press, New York, 1965, pp. 325-341. 
Table 1. - Prototype OTV $\mathrm{LH}_{2}$ Tankage Characteristics

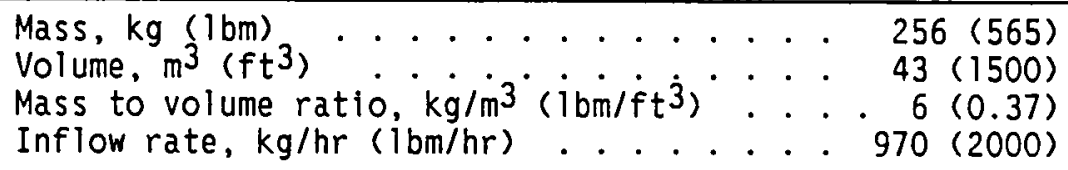

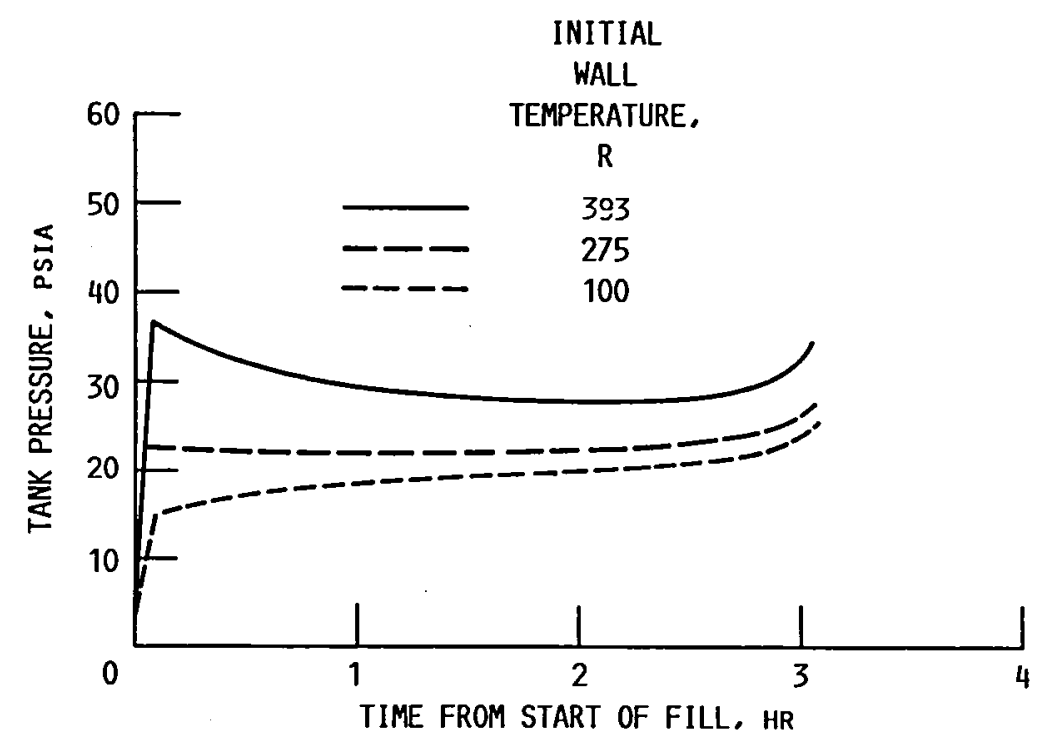

FIGURE 1. - EFFECT OF INITIAL WALL TEMPERATURE ON THE NOVENT FILL PROCESS. PROTOTYPE OTV LH2 TANKAGE: TANK VOLUME $1500 \mathrm{CU} F \mathrm{FT}$; MASS TO VOLUME, $0.3 \mathrm{LBM} / \mathrm{CU} \mathrm{FT}$ : INFIOW. 2000 LBM/HR: INFLOW TEMPERATURE, $36.6 \mathrm{R}$; HEA.T TRANSFER COEFFICIENT, $10 \mathrm{BTY} / \mathrm{SQ}$ FT-HR-R. 


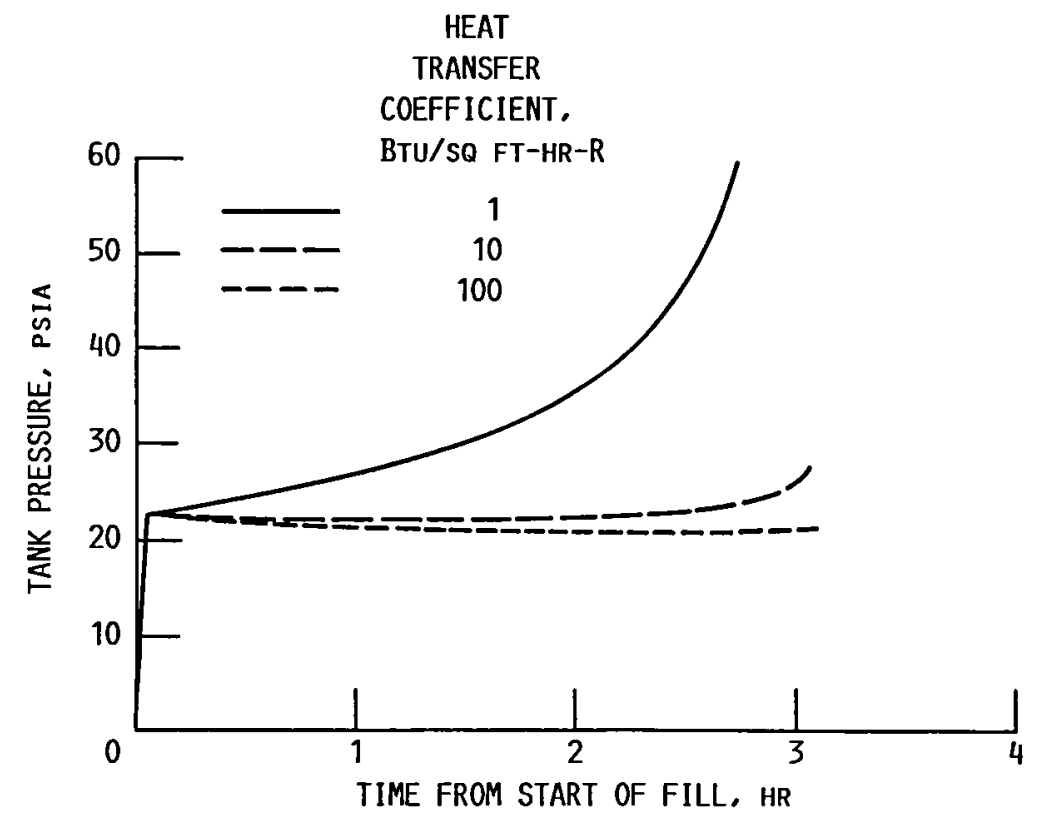

FIGURE 2. - EFFECT OF INTERFACIAL HEAT TRANSFER COEFFICIENT ON THE NO-VENT FILL PROCESS. PROTOTYPE OTV LH2 TANKAGE; TANK VOLUME $1500 \mathrm{CU} F \mathrm{FT}$; MASS TO VOLUME $0.3 \mathrm{LBM} / \mathrm{CU} \mathrm{FT}$ : INFLOW, $2000 \mathrm{LBM} / \mathrm{HR}$ : INFLOW TEMPERATURE, $36.6 \mathrm{R}$; INITIAL TANK WALL TEMPERATURE. 275 R.

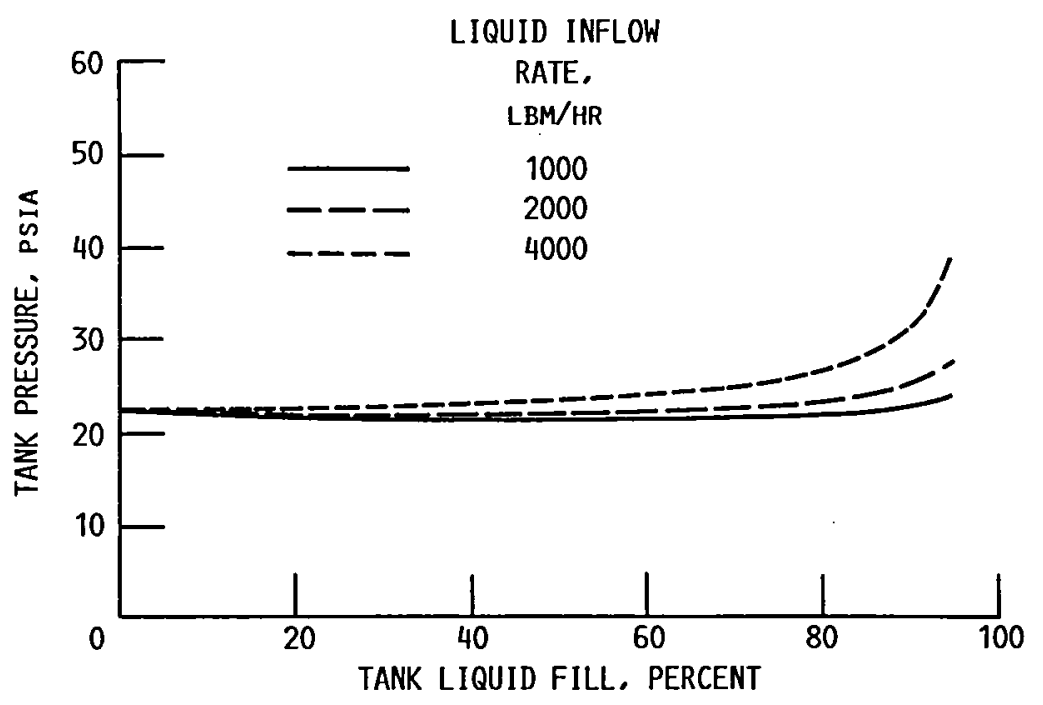

FIGURE 3. - EFFECT OF LIQUID INFLOW RATE ON THE NO-VENT FILL PROCESS. PROTOTYPE OTV LH2 TANKAGE: TANK VOLUME $1500 \mathrm{CU} F T$ : MASS TO VOLUME, 0.3 LBM/CU FT: INITIAL WALL TEMPERATURE, $275 \mathrm{R}$ : INFLOW TEMPERATURE, $36.6 \mathrm{R}$ : HEAT TRANSFER COEFFICIENT, $10 \mathrm{BTU} / \mathrm{SO}$ FT-HR-R. 


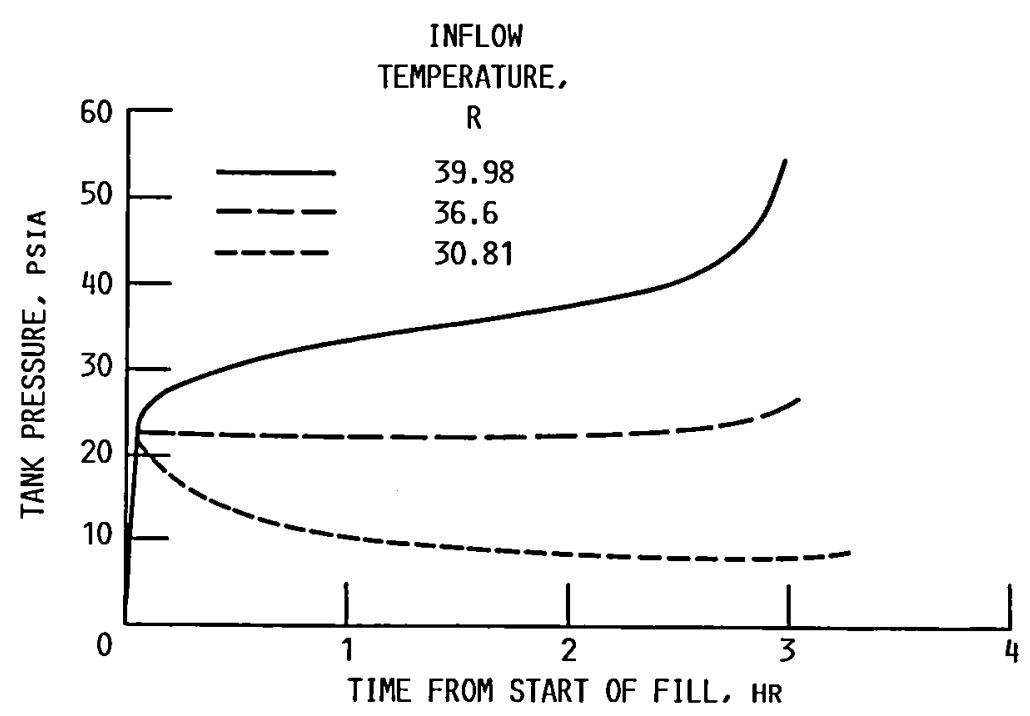

FIGURE 4. - EFFECT OF INFLOWING LIQUID TEMPERATURE ON THE NO-VENT FILL PROCESS. PROTOTYPE OTV TANKAGE: TANK VOLUME $1500 \mathrm{CU} F T$ : MASS TO VOLUME, $0.3 \mathrm{LBM} / \mathrm{CU} \mathrm{FT}$ : INFLOW, 2000 LBM/HR: INITIAL WALL TEMPERATURE, $275 \mathrm{R}$; HEAT TRANSFER COEFFICIENT, $10 \mathrm{BTU} / \mathrm{SQ}$ FT-HR-R. 


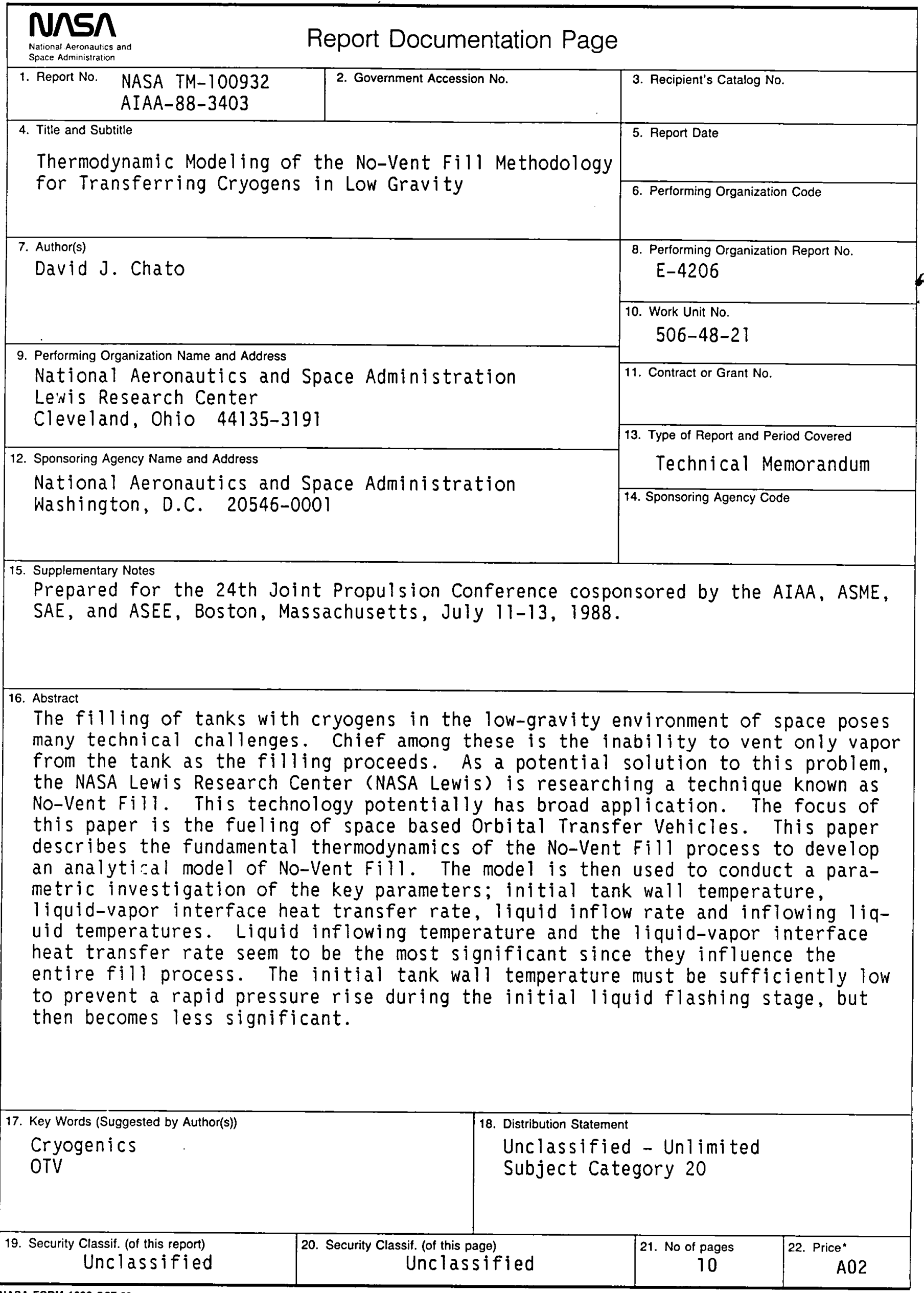


National Aeronautics and Space Administration

Lewis Research Center

Cleveland, Ohio 44135

Officlal Business

Penalty for Private Use $\$ 300$

\section{ADDRESS CORRECTION REQUESTED}

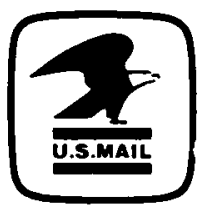

Postage and Fees Paid National Aeronautics and

Space Administration

NASA.451 